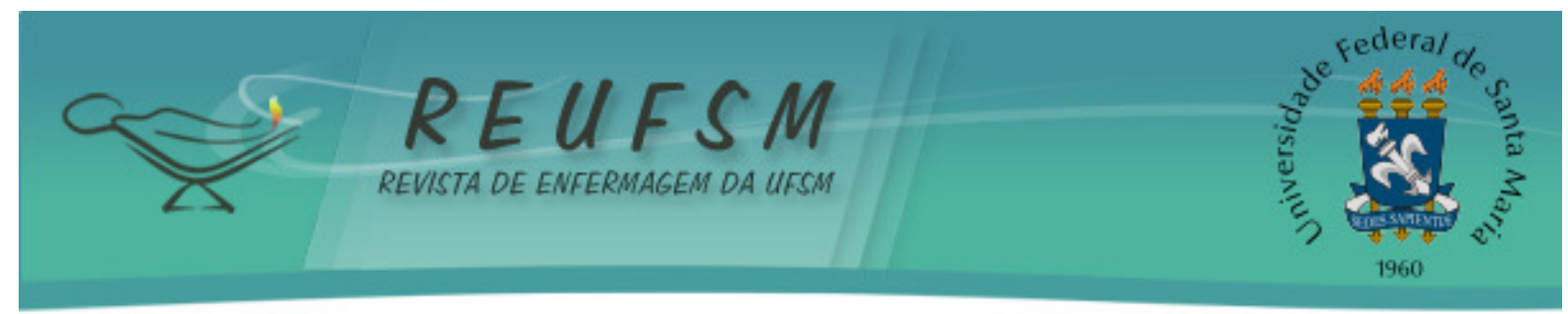

ARTIGO ORIGINAL

\title{
SABERES E PRÁTICAS DE PESSOAS COM ÚLCERA VENOSA EM TRATAMENTO COM BOTA DE UNNA
}

AWARENESSES AND PRACTICES OF PEOPLE WITH VENOUS ULCERS IN TREATMENT WITH
UNNA BOOT

\section{CONOCIMIENTOS Y PRÁCTICAS DE PERSONAS CON ÚLCERA VENOSA EN EL} TRATAMIENTO CON BOTA DE UNNA

\author{
Marianne Lopes Robaina ${ }^{1}$ \\ Maria de Lourdes Denardin Budó ${ }^{2}$ \\ Dalva Cezar da Silva ${ }^{3}$ \\ Maria Denise Schimith ${ }^{4}$ \\ Vânia Lúcia Durgante ${ }^{5}$ \\ Bruna Sodré Simon ${ }^{6}$
}

Doi: $10.5902 / 2179769221985$

RESUMO: Objetivo: descrever os saberes e práticas de pessoas com úlcera venosa em tratamento com bota de Unna. Método: pesquisa qualitativa e descritiva. Realizada no ambulatório de angiologia de um hospital universitário no Rio Grande do Sul, Brasil. A coleta dos dados ocorreu em outubro e novembro de 2013, com oito pessoas, por meio de entrevista semiestruturada, fichas de avaliação de lesões e prontuários. Utilizou-se a análise de conteúdo temática no tratamento dos dados. Resultados: os saberes se relacionam à causa circulatória e as práticas, com o repouso e a cicatrização da úlcera venosa. A bota de Unna foi citada como tratamento benéfico e facilitador, embora possa proporcionar algum incômodo. Conclusão: os entrevistados referiram conhecimento sobre a origem da lesão, realizavam práticas de cuidado para melhora no retorno venoso e a bota de Unna foi considerada um tratamento benéfico.

DESCRITORES: Doença crônica; Úlcera varicosa; Enfermagem.

ABSTRACT: Aim: to describe the knowledge and practices of people with venous ulcers in treatment with Unna boot. Method: qualitative and descriptive research. It was developed in an angiology outpatient clinic of a university hospital in Rio Grande do Sul, Brazil. The data collection occurred in October and November 2013 with eight people, through semi-structured interview, injury evaluation forms and medical records. It was used the thematic content analysis in data processing. Results: the knowledges were related to the circulatory cause and practices, with rest and the healing of venous ulcers.

\footnotetext{
1 Enfermeira. Mestre em Enfermagem pelo Programa de Pós-Graduação em Enfermagem da Universidade Federal de Santa Maria (PPGEnf/UFSM). Santa Maria, RS, Brasil. E-mail: mari.robaina@hotmail.com

2 Enfermeira. Doutora em Enfermagem. Professora Aposentada do Departamento de Enfermagem da Universidade Federal de Santa Maria. Santa Maria, RS, Brasil. E-mail: lourdesdenardin@gmail.com

3 Enfermeira no Departamento de Enfermagem da Universidade Federal de Santa Maria. Doutoranda em Enfermagem pela Universidade Federal do Rio Grande do Norte. Santa Maria, RS, Brasil. E-mail: dalvacezarsilva@yahoo.com.br

${ }^{4}$ Enfermeira. Doutora em Ciências. Professora no Departamento de Enfermagem da Universidade Federal de Santa Maria. Santa Maria, RS, Brasil. E-mail: ma.denise2011@gmail.com

${ }^{5}$ Enfermeira no Hospital Universitário de Santa Maria, Serviço Ambulatorial Ala A. Mestre em Enfermagem pelo PPGEnf/UFSM. Santa Maria, RS, Brasil. E-mail: vaniadurgante@yahoo.com.br

${ }^{6}$ Enfermeira. Professora Assistente do Curso de Graduação em Enfermagem da Universidade Federal do Pampa (UNIPAMPA). Mestre em Enfermagem pelo PPGEnf/UFSM. Uruguaiana, RS, Brasil. E-mail: enf.brusimon@gmail.com
} 


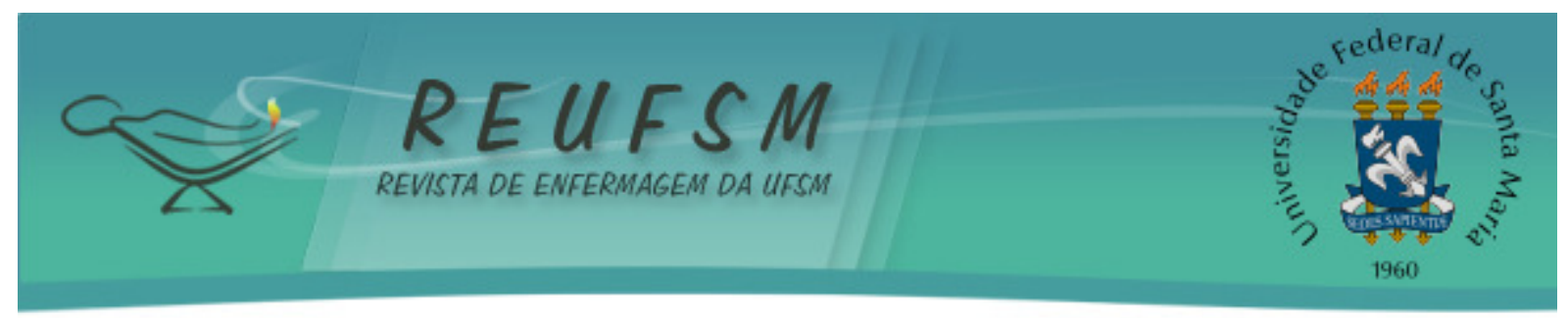

The Unna boot was mentioned as beneficial and facilitating treatment, although it can cause some discomfort. Conclusion: the interviewed patients reported to have awareness about the origin of the lesion, performed care practices to improve the venous return and the Unna boot was considered a beneficial treatment.

DESCRIPTORS: Chronic disease; Varicose ulcer; Nursing.

RESUMEN: Objetivo: describir los conocimientos y prácticas de personas con úlceras venosas en el tratamiento con bota de Unna. Método: investigación cualitativa y descriptiva. Realizada en clínica de angiología de un hospital universitario del Rio Grande do Sul, Brasil. La recolección de datos ocurrió entre Octubre y Noviembre de 2013, con ocho personas, a través de entrevista semiestructurada, formularios de evaluación de lesiones y registros médicos. Se utilizó el análisis de contenido temático en el procesamiento de datos. Resultados: los conocimientos se relacionan al origen circulatorio y las prácticas, con el reposo y la cicatrización de las úlceras venosas. La bota de Unna fue citada como tratamiento beneficioso y facilitador, aunque pueda proporcionar algún inconveniente. Conclusión: los interrogados informaron conocimiento sobre el origen de la lesión, realizaron prácticas de atención para mejorar el retorno venoso. La bota de Unna se consideró un tratamiento beneficioso.

DESCRIPTORES: Enfermedad crónica; Úlcera varicosa; Enfermería.

\section{INTRODUÇÃO}

A úlcera venosa apresenta elevada incidência e prevalência, é de difícil e prolongado tratamento, se manifesta em pessoas com insuficiência venosa crônica dos membros inferiores e, frequentemente, se apresenta associada à presença de varizes. ${ }^{1}$ Por ser uma condição crônica, necessita de cuidados e mudanças no estilo de vida da pessoa acometida.

Para que tais mudanças ocorram, é importante que essa pessoa amplie seus conhecimentos sobre o processo saúde-doença, e se sinta preparada para se cuidar. Com a finalidade de auxiliar no tratamento, considera-se relevante que a pessoa tenha consciência da necessidade de adquirir hábitos saudáveis, dos cuidados para evitar complicações e também sobre a sua responsabilidade com a própria saúde. ${ }^{2}$

Um dos principais tratamentos para úlcera venosa se trata da terapia compressiva, a qual favorece o retorno venoso, sendo fundamental na cicatrização deste tipo de ferida. Essa medida terapêutica auxilia na diminuição da hipertensão venosa e pode ser realizada com o uso de meias de compressão, faixa elástica ou bota de Unna. ${ }^{3}$

A bota de Unna é um tratamento compressivo inelástico utilizado em serviços ambulatoriais, que se constitui por uma gaze impregnada com glicerina, gelatina e óxido de zinco. ${ }^{1}$ Ao utilizar essa medida terapêutica, faz-se necessário o acompanhamento semanal no serviço de saúde, para a troca deste tipo de bandagem. ${ }^{4}$ A colocação da bota de Unna ocorre após a higienização da úlcera com soro fisiológico, com o paciente já posicionado para aumentar a pressão hidrostática intravascular e auxiliar na diminuição do efeito do ortostatismo prolongado. Indica-se a aplicação da bandagem no sentido do tornozelo para o joelho e com compressão externa no membro inferior. Após, aplica-se a atadura e se fixa com fita crepe. ${ }^{1,3}$

Os aspectos culturais e sociais das pessoas podem interferir no modo de vivenciar os processos de saúde e doença. A maneira como elas enfrentam este processo influencia em suas práticas de cuidado. Por isso, destaca-se a importância de articular saberes profissionais e populares, recursos institucionais e comunitários, iniciativas públicas e privadas, para superar o conceito biomédico de assistência à saúde, além de incentivar o desenvolvimento da consciência crítica das pessoas sobre a necessidade da luta por direitos à saúde. ${ }^{5}$ 


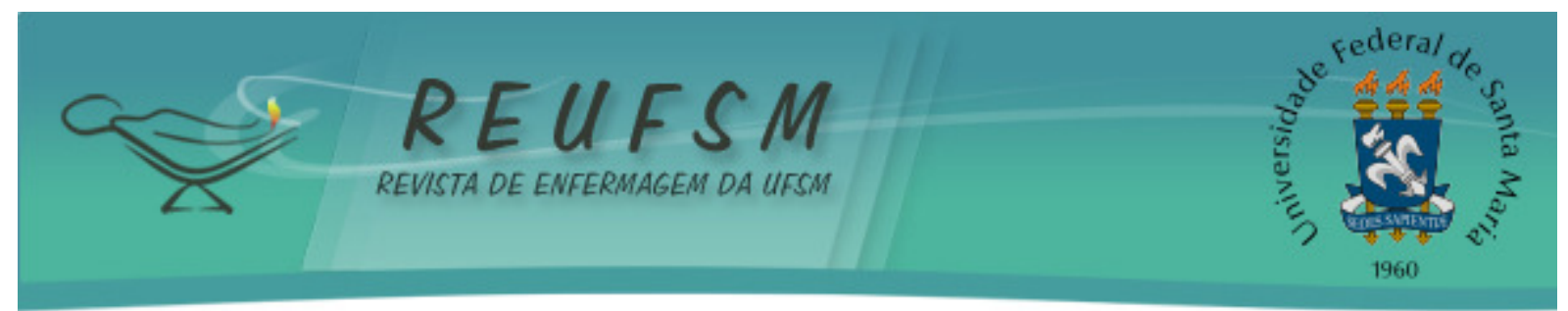

Por meio da educação em saúde, pode-se proporcionar oportunidades de reflexão sobre práticas de cuidados e mudanças de costumes, constituindo-se um dos pilares da promoção da saúde. ${ }^{6}$ Para que a prática em educação em saúde atinja seus objetivos é imprescindível que haja troca de saberes entre as pessoas e os profissionais. Ao compartilhar informações, crenças, valores e normas, espera-se atender às necessidades da população, bem como orientar as ações dos profissionais de saúde. Ao cuidar de pessoas com úlcera venosa, é necessário identificar as características e os diversos aspectos, a fim de compreender as peculiaridades e o contexto de cada uma delas. ${ }^{7}$

Assim, conhecer a realidade das pessoas em tratamento com bota de Unna pode auxiliar no planejamento do cuidado adaptado às necessidades de cada pessoa cuidada. Pautada nessas considerações, questiona-se: quais os saberes e as práticas de pessoas com úlcera venosa em tratamento com bota de Unna? Nesse sentido, objetivou-se descrever os saberes e práticas de pessoas com úlcera venosa em tratamento com bota de Unna.

\section{MÉTODO}

Pesquisa qualitativa e descritiva, realizada em um ambulatório de angiologia de um hospital universitário, centro de referência secundária e terciária em saúde, pertencente ao serviço público de saúde no Rio Grande do Sul, Brasil.

No período de coleta dos dados, em outubro e novembro de 2013, estavam cadastradas no serviço dez pessoas com úlcera venosa em tratamento com bota de Unna. Elegeram-se como critérios de inclusão: apresentar úlcera venosa; ter 18, ou mais, anos de idade; estar em acompanhamento no referido ambulatório e em uso de bota de Unna. Como critérios de exclusão: pessoas com algum tipo de dificuldade de comunicação e aquelas que estavam em tratamento na sua cidade de origem.

O convite para participar da pesquisa ocorreu no ambulatório durante a espera por atendimento, como consultas ou curativos. Duas das dez pessoas cadastradas realizavam a retirada da bota de Unna, mas estavam em tratamento em seu munícipio de origem, sendo assim, participou da pesquisa um total de oito pessoas.

Para a coleta de dados, utilizou-se a entrevista semiestruturada, as fichas de avaliações de lesões e os prontuários. A entrevista foi realizada de maneira individual, em sala do próprio ambulatório, e versava a caracterização dos participantes, conhecimentos sobre a úlcera venosa, práticas de cuidados e sua experiência no tratamento com a bota de Unna. As entrevistas foram, primeiramente, registradas em um gravador digital de áudio, para posteriormente serem transcritas e analisadas.

No tratamento dos dados se utilizou a análise temática, que envolve a pré-análise, a exploração do material e o tratamento dos resultados obtidos e interpretação. ${ }^{8}$ Assim, foi realizada leitura flutuante das entrevistas, sendo identificadas as ideias centrais; selecionados trechos significativos das falas e, por meio da leitura e releitura, desenvolveu-se a codificação cromática dos achados. Foram construídas categorias temáticas, pelas quais se destacaram as convergências, divergências e semelhanças das falas dos participantes. A análise final consistiu em articular o corpus estruturado à fundamentação teórica, visando à identificação do conteúdo subjacente ao manifestado, na tentativa de responder ao objetivo.

Quanto aos aspectos éticos, as pessoas foram convidadas verbalmente para participar da pesquisa, sendo informados dos objetivos da mesma e da não obrigatoriedade de sua participação; após o consentimento prévio dos entrevistados, o Termo de Consentimento Livre e Esclarecido foi assinado. 0 projeto de pesquisa foi aprovado pelo Comitê de Ética e Pesquisa com Seres Humanos da instituição, com Certificado de Apresentação para Apreciação Ética $n^{\circ}$ 21335713.1.0000.5346 e número de parecer 395.228. Os participantes foram identificados pela letra $E$ (entrevistado), seguida do 


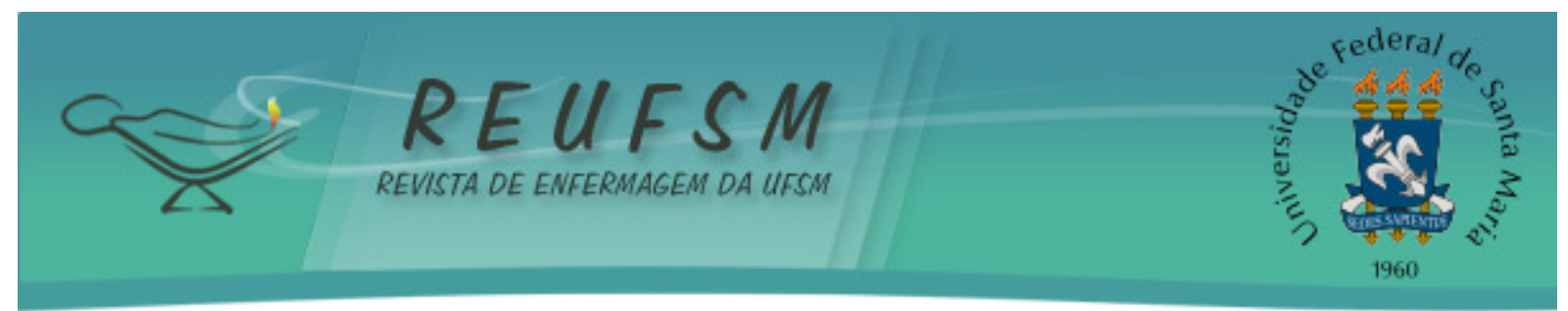

número indicativo da ordem da entrevista, além das letras $\mathrm{M}$ e $\mathrm{F}$ para indicar o sexo, e a idade em anos. $O$ estudo atendeu à Resolução $n^{\circ}$. 466/12, do Conselho Nacional de Saúde no Brasil, que dispõe sobre as questões éticas em pesquisa envolvendo seres humanos.

\section{RESULTADOS}

Dos oito participantes da pesquisa, quatro eram do sexo feminino e quatro do sexo masculino, cinco tinham 60 anos ou mais, com tempo de existência da úlcera variando de um a 22 anos, e o tempo de uso da bota de Unna de oito dias a três anos. Um participante não soube informar o tempo de uso da bota de Unna, nem foram encontrados dados a respeito disso na ficha de avaliação de lesões, nem no prontuário. Os entrevistados deste estudo, em geral, apresentaram pouca escolaridade e baixa renda.

$\mathrm{Na}$ análise dos dados, destacaram-se duas categorias: Saberes de pessoas com úlcera venosa em tratamento com bota de Unna; e Práticas de cuidado de pessoas com úlcera venosa e a experiência com a bota de Unna.

\section{Saberes de pessoas com úlcera venosa em tratamento de bota de Unna}

Em relação aos saberes, surgiram as concepções sobre a origem da lesão, que foram decorrentes de problemas circulatórios e do desconhecimento sobre o que poderia ter ocasionado a úlcera venosa.

Ao relacionar a origem da úlcera aos problemas circulatórios, destacaram-se os seguintes relatos:

[A causa da] úlcera venosa é a circulação, no meu caso aqui a circulação periférica, ela não retorna e o retorno venoso não é o ideal, o adequado, aí acontece isso, abre. (E2, F, 61 anos)

diz que é de má circulação, agora mesmo a enfermeira estava me dizendo que eu tinha que caminhar mais um pouco, mas eu tenho medo de caminhar e a ferida aumentar. (E4, F, 54 anos)

Além de relacionar o surgimento da úlcera venosa com problemas circulatórios, são descritas características e alterações vivenciadas pelas pessoas com úlcera venosa:

foi decorrido da trombose, eu tive a trombose, na sequência deu escurecimento da perna, uma das veias rompeu. Como diz, a ponta da veia apodreceu, e parece que sempre brota, não morre totalmente [a úlcera]. (E6, M, 47 anos)

A relação feita da origem da lesão com causas secundárias, como trombose, pode ser identificada ao expressar o conhecimento sobre a ocorrência de recidivas "a ponta da veia apodreceu, e parece que sempre brota". As recidivas se constituem um problema na assistência às pessoas com úlcera venosa, neste estudo se identificou que cinco pessoas tiveram reincidência, a partir dos dados das fichas de avaliação e prontuários.

A existência de varizes também foi relacionada com o surgimento da úlcera, principalmente após a ocorrência de traumas: 


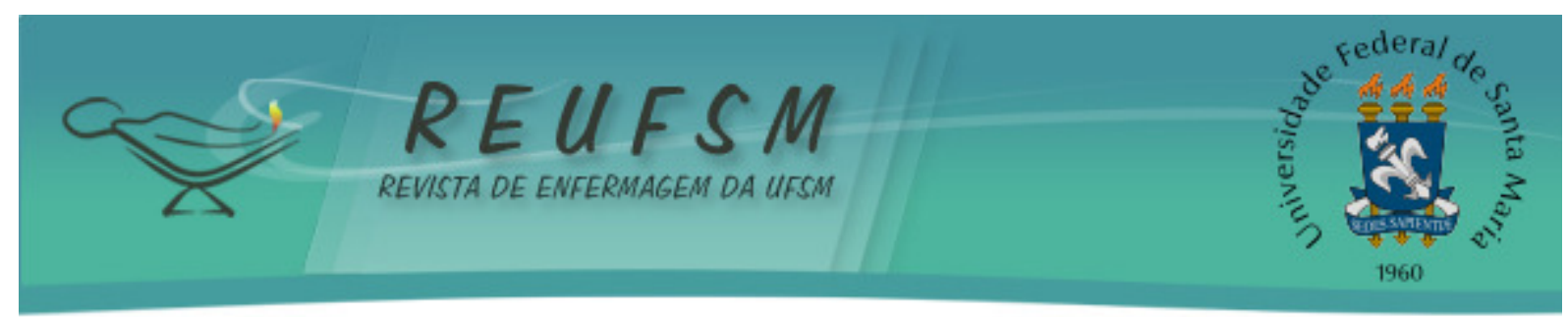

foi das varizes que rebentou, eu trabalhava de faxineira, e cai de bicicleta e daí que começou, rebentou as varizes e não teve mais assim de fechar. (E7, F, 60 anos)

arranhou, bateu ali [sinaliza o local da ferida], e o machucado parece que puxa, a gente tem um machucado e sempre bate ali, como vai sarar? (E8, M, 68 anos)

Contatou-se que a ocorrência de trauma é frequentemente relacionada à origem da úlcera e às recidivas, pelos entrevistados. Também, foram referidos como a causa da lesão os "fatores relacionados ao sangue":

eu não sei, eu acho que deve ser do sangue sujo, outros dizem que é parte da circulação, acho que não é da circulação, por que se fosse circulação ia ser mais grave. Também é ácido, estas coisas de ácido, me sentia mal, agora não tenho sentido assim, até estou tomando um AAS [Ácido Acetil Salicílico], para sarar este negócio. A enfermeira diz que eu preciso tomar o AAS que o sangue está muito [pensa] que podia dar até uma trombose, e que tinha que tomar para o sangue ficar meio assim, agitado. (E8, M, 68 anos)

Identificou-se que o participante acredita que seu problema decorre do "sangue sujo" e este "diagnóstico" se baseia em simbolismo popular. O entrevistado pontua que se seu problema fosse circulatório seria mais grave, embora muitas pessoas, inclusive a enfermeira citada, já tenham informado que as lesões são decorrentes de problemas circulatórios.

Por outro lado, destacou-se nas falas de participantes o desconhecimento sobre a causa da úlcera venosa:

não sei nada, nem sei explicar, [risos] eu sei o que falam, mas saber explicar para os outros eu não sei. (E1, F, 64 anos)

[...] não tenho ideia, nunca explicaram o que é. (E3, M, 54 anos)

Estas pessoas referem ter pouco conhecimento sobre sua doença, essa afirmativa pode ser decorrente do constrangimento que poderiam sentir ao responder de forma "errada" à pergunta.

Práticas de cuidado de pessoas com úlcera venosa e a experiência com a bota de Unna

Dentre as práticas de cuidado realizadas pelas pessoas com úlcera venosa em tratamento com bota de Unna foram descritas: repouso, elevação do membro acometido, atividade física e evitar o sobrepeso. Em relação ao repouso, destacaram-se as falas:

quando começa a dor eu tenho que deitar, tenho que sentar e isso durante o dia. (E6, M, 47 anos)

tenho costume de deitar meio dia um pouquinho. (E7, F, 60 anos) 


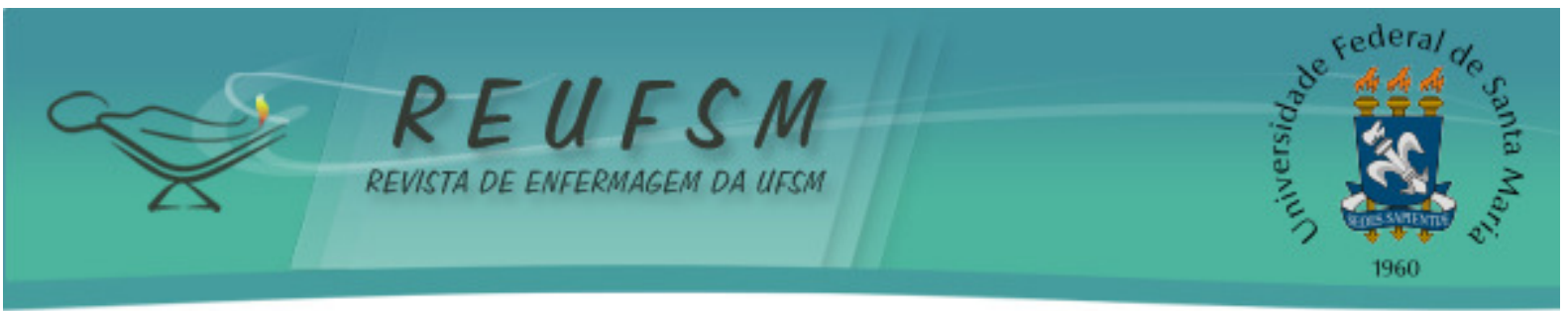

Estas pessoas referem realizar o repouso durante o dia, por períodos, seja pela necessidade, devido à dor ou pela rotina incorporada ao cuidado.

Também, os entrevistados referiram não realizar o repouso o suficiente ou apenas à noite, enquanto dormem:

vou te falar bem a verdade, o repouso para mim é só à noite mesmo. (E2, F, 61 anos)

muitos dizem que é para erguer os pés [...] só que eu não consigo ficar parado, só dormindo mesmo. (E8, M, 68 anos)

Há dificuldade em realizar o repouso durante o dia e as diferentes razões necessitam ser investigadas.

A elevação dos membros inferiores também foi uma prática de cuidado relatada pelos entrevistados:

ficar o máximo de tempo possível com a perna para cima. (E3, M, 54 anos)

tem que cuidar, parar mais com o pé levantado. (E5, M, 69 anos)

Os entrevistados demonstraram o conhecimento sobre a importância da elevação dos membros inferiores, como forma de cuidado. Porém, a maneira como a elevação do membro se realizava nem sempre era adequada:

levantar a perna assim [demonstra sentada, elevando a perna até a altura do quadril]. (E1, F, 64 anos)

Elevar o membro acometido foi considerada uma prática de cuidado para melhora do retorno venoso. Entretanto, conforme a maneira que foi descrita, pode dificultar ainda mais essa prática.

Ainda, a atividade física foi referida como prática de cuidado de algumas pessoas que tem úlcera e não possuem contra indicação para realizá-la.

Eu tenho que caminhar, dar mais uma caminhadinha, mas eu caminho em casa. (E4, F, 54 anos)

Fazer exercício, agora já voltei de novo para terceira idade [grupo de idosos]. (E1, F, 64 anos)

A atividade física foi citada por estas entrevistadas por meio de caminhadas ou atividades em grupo de idosos. Destaca-se que depois da entrevista foi realizada a orientação de como o repouso deve ser feito e dos benefícios da atividade física.

Outras práticas referidas foram evitar o sobrepeso e cuidar da alimentação:

eu me trato na nutricionista, já perdi uns $5 \mathrm{~kg}$, o doutor [médico] disse que tenho que perder esta barriga por causa das pernas. (E4, $\mathrm{F}, 54$ anos) 


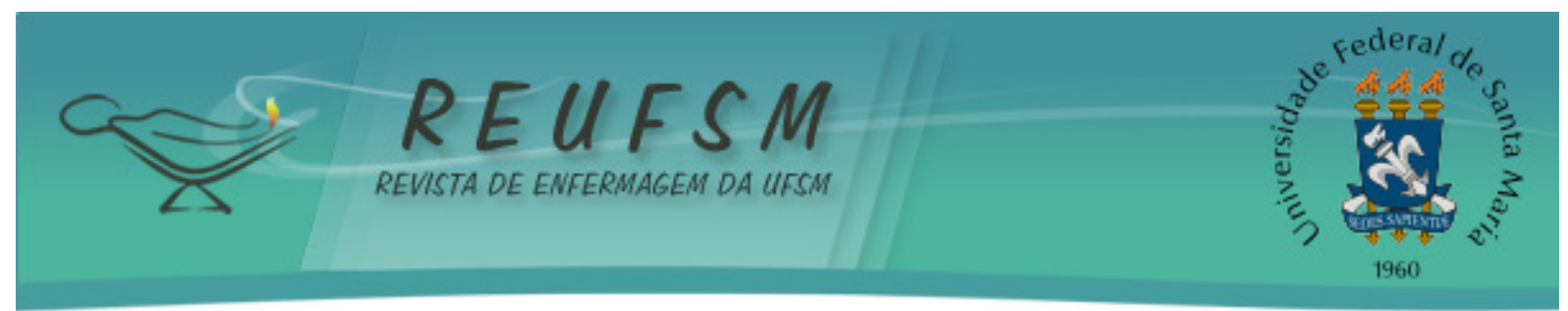

o doutor [médico] sempre diz que não dá para ficar muito gordo, que a gordura atrapalha as pernas da gente. (E7, F, 60 anos)

As entrevistadas referiram ter recebido orientação do médico e da nutricionista sobre a necessidade de perder peso e o cuidado da alimentação, relacionado à úlcera. Isso ocorre ao se compreender que as participantes evidenciam que o sobrepeso "atrapalha as pernas".

Quanto ao uso da bota de Unna os entrevistados pontuaram as facilidades e dificuldades encontradas ao utilizar este tipo de tratamento. Em relação às facilidades referiram que:

com a bota não precisa estar mexendo todo dia, a gente troca só este de fora, mas a bota mesmo fazem aqui no ambulatório, a gente não precisa mexer, a bota ajudou muito. (E2, F, 61 anos)

é bem fácil, adorei porque parece que cicatriza mais ligeiro, a medicação esta toda ali na bota (E4, F, 54 anos).

A utilização da bota de Unna foi considerada fácil por não necessitar de troca diária e por favorecer o processo de cicatrização.

Destaca-se que com o uso da bota de Unna foi possível a diminuição da dor e do edema conforme os relatos:

é mais fácil, porque eu não sinto nada da perna [dor], foi melhor [com o uso da bota]. (E3, M, 54 anos)

antes sentia muita dor, o pé inchava e não podia colocar calçado, mudou bastante depois que comecei a usar a bota. (E1, M, 64 anos)

A diminuição da dor e do edema com o uso da bota de Unna foram destacados como aspectos favoráveis promovidos pelo tratamento. desconforto:

Porém, para algumas pessoas o uso da bota de Unna envolve dificuldades e

senti-me mais obrigado a repousar, porque ela aperta e incomoda. (E6, M, 47 anos)

\section{[...] tem que estar fechado e é quente. (E7, F, 60 anos)}

eu acho ruim porque tem que botar um monte de atadura ali, não sei por que botam até lá em cima [abaixo do joelho], porque lá em cima não tem machucado, é só para baixo, mas diz que tem que ser assim. (E8, M, 68 anos)

O entrevistado E8 demostrou desagrado com a quantidade de material utilizado no curativo e a necessidade de ser realizado até abaixo do joelho, considerando isso ruim. Além disso, a bota de Unna em alguns casos causa incômodo e desconforto devido à aderência e inelasticidade do tratamento, motivo pelo qual as pessoas relataram desconforto ao utilizá-lo, principalmente em dias quentes, pois o curativo fica fechado por cerca de uma semana, dificultando a transpiração. 


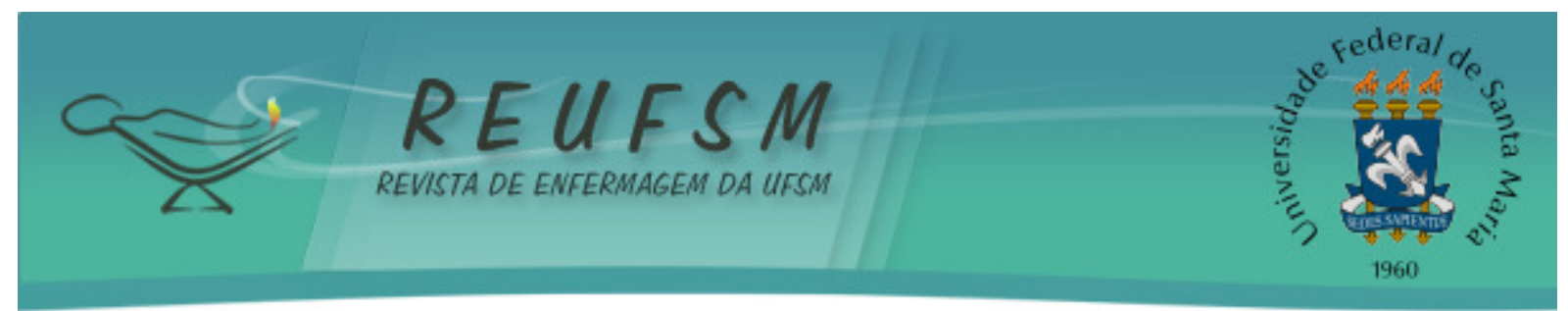

DISCUSSÃO

A pouca escolaridade e baixa renda de pessoas com úlcera venosa são pontos que podem influenciar nos saberes e práticas ao desenvolver seus cuidados. Além disso, o não entendimento sobre os cuidados orientados pode resultar na adesão incorreta ou não adesão ao tratamento indicado. Torna-se importante que se conheçam as características das pessoas para que sejam planejadas propostas de intervenção, sendo que elas, na sua singularidade, são consideradas no tratamento. Logo, tem-se essa condição essencial na adesão e continuidade do tratamento proposto. ${ }^{9}$

Identificou-se que a deficiência no retorno venoso foi citada pelos entrevistados como a principal causa do aparecimento da úlcera. Embora não sejam conhecidos exatamente os mecanismos fisiopatológicos responsáveis pelo surgimento da úlcera venosa, tem-se que a insuficiência venosa crônica seja a origem mais comum. Quando o funcionamento do sistema venoso é prejudicado, pode causar um quadro de hipertensão venosa, surgindo alterações como edema, hiperpigmentação e a lipodermatoesclerose, favorecendo o aparecimento da úlcera. ${ }^{10-11}$

0 motivo das recidivas advém, em alguns casos, do desconhecimento sobre a importância de manter técnicas adequadas para melhora do retorno venoso, como o uso de meias elásticas após a cicatrização da lesão. ${ }^{4}$ Assim, é necessário que o profissional de saúde realize orientações valorizando os saberes populares e respeitando as particularidades, utilizando uma linguagem que torne possível à pessoa e seus familiares compreender as informações que lhes são transmitidas. ${ }^{9}$ A compreensão da importância dos cuidados após a cicatrização da lesão pode possibilitar à pessoa dar continuidade ao tratamento, evitando assim o ressurgimento da úlcera.

Estudo $^{12}$ realizado em uma Unidade Básica de Saúde do Distrito Federal mostrou que assim como a hipertensão, as varizes são relacionadas com o surgimento da úlcera venosa. O conhecimento de tal fato é importante para que se desenvolvam ações preventivas em pessoas que possuem as doenças predisponentes.

Outra questão é o envelhecimento populacional, pois com o passar da idade surgem algumas alterações na pele como perda da sensibilidade, diminuição da elasticidade, ressecamento e distúrbios na termorregulação. Essas modificações fisiológicas, somadas às alterações na circulação sanguínea, tornam a pele dos idosos mais frágil e susceptível a desenvolver úlceras crônicas. Também, a pele mais frágil faz com que os traumas, mesmo que pequenos, originem uma nova lesão. ${ }^{13}$

Para que os profissionais de saúde possam aproximar seus conhecimentos aos da população, contribuindo para a criação de vínculo e o atendimento integral, é necessário ampliar o conhecimento, respeitar a cultura e entender que cada pessoa tem uma percepção diferente sobre as coisas. Em uma pesquisa realizada em Fortaleza, Ceará, constatou-se que o desconhecimento das pessoas com úlcera venosa sobre a insuficiência venosa, pode diminuir as chances de eficácia do tratamento. ${ }^{14}$

As orientações realizadas pelo profissional são essenciais para o tratamento da úlcera venosa, pois a pessoa com esta lesão se torna ativa nesse processo, estendendo os cuidados da unidade de saúde para seu domicílio. ${ }^{13}$ As estratégias educativas, como desencorajar a automedicação, estimular o repouso, exercícios e elevação dos membros, devem ser utilizadas pelos profissionais para contribuir com a melhora da saúde. ${ }^{15}$

Nesse sentido, o apoio da família se torna indispensável no cuidado à pessoa com úlcera venosa, já a ausência pode contribuir para a cronicidade da lesão. ${ }^{16}$ Ainda, o apoio da família contribui para a melhor aceitação da condição de saúde e adesão ao tratamento. A existência da úlcera venosa costuma repercutir no abandono do trabalho ou 


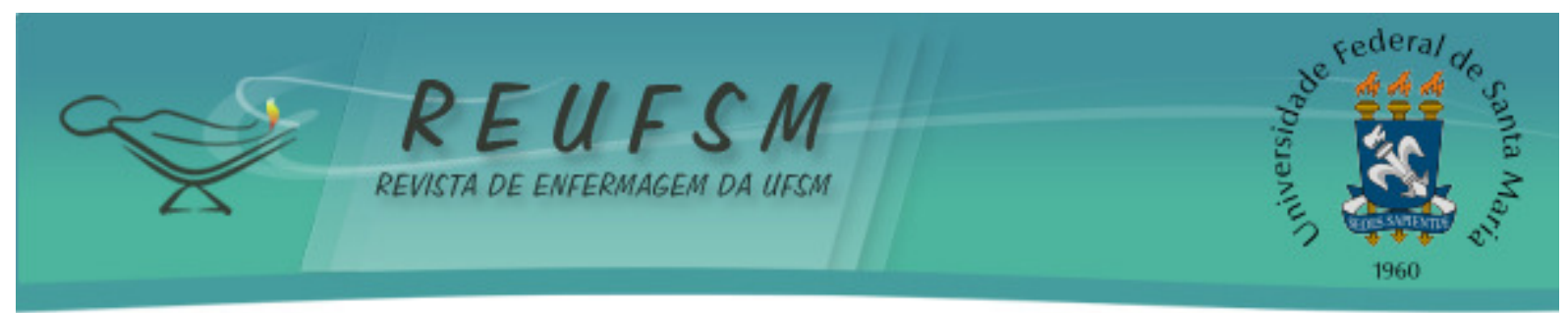

estudo e no afastamento das atividades diárias e de lazer, interferindo negativamente sobre a qualidade de vida. ${ }^{14}$

Identificou-se que o conhecimento sobre a importância de determinados cuidados nem sempre se tornou prática regular e adequadamente realizada pelas pessoas com úlcera venosa em tratamento com bota de Unna. Uma questão que exemplifica essa constatação foi a referência ao repouso e à elevação dos membros inferiores. A elevação dos pés acima da altura do coração colabora para a diminuição do edema e melhora da microcirculação, a gravidade auxilia no transporte do sangue venoso. Portanto, quando a pessoa diz se sentar e elevar a perna sobre uma cadeira, ocorre a compressão das veias na região inguinal, o que dificulta o retorno venoso. ${ }^{4}$

Praticar exercícios físicos leves como caminhadas regulares, ou exercícios específicos para as pernas, sem o levantamento de peso, contribui para a diminuição do peso corporal. Também, favorece o processo de cicatrização, pois durante a caminhada a compressão dos músculos da perna, conhecida como "bomba de panturrilha", impulsiona o sangue, direcionado pelas válvulas das veias no sentido do coração, o que auxilia no retorno venoso. ${ }^{17}$

O excesso de peso pode contribuir para o desenvolvimento da úlcera venosa, por ser um fator de risco para insuficiência venosa crônica, principal causador da doença. Também são considerados fatores de risco para o desenvolvimento de úlcera venosa: hipertensão arterial, Diabete Mellitus, sedentarismo, tabagismo e etilismo. Essas informações são relevantes e devem ser consideradas pelos profissionais da saúde, destacando-se os de enfermagem, para o desenvolvimento de orientações, potencializando as de educação em saúde e na elaboração de diretrizes para o seguimento e tratamento. ${ }^{18}$

Destaca-se que o uso da terapia compressiva deve ser acompanhado por médico, enfermeiro e outros profissionais de saúde capacitados para aplicá-la, para que apresente resultados favoráveis. ${ }^{4}$ A compressão exercida pela bota de Unna diminui o edema, ao minimizar o refluxo e aumentar a velocidade do fluxo venoso, propiciando reabsorção do excesso de líquido no interstício. ${ }^{12} \mathrm{Em}$ relação ao custo, mesmo sendo mais elevado em relação a outros tratamentos, a bota de Unna requer um número reduzido de trocas, o que compensa o valor deste produto. ${ }^{10}$

Para diminuir o desconforto ocasionado pelo uso da bota de Unna, faz-se necessário que o profissional que irá realizar o curativo esteja capacitado para isso. o manuseio inadequado causa dor e desconforto, não contribui para a eficácia do tratamento. ${ }^{19}$ Para tanto, ao considerar a complexidade deste tratamento, verificou-se que os profissionais necessitam incorporar a educação em saúde em suas práticas, o que potencializa o tratamento da pessoa com úlcera venosa no serviço especializado.

\section{CONCLUSÃO}

Constatou-se que os entrevistados tinham, em geral, conhecimento de que a origem da úlcera decorre de problema na circulação. Quanto às práticas de cuidado, eles demonstraram conhecer a necessidade de repouso para a melhora no retorno venoso e cicatrização da úlcera venosa. No entanto, estas práticas nem sempre eram feitas adequadamente, ou devido à falta de entendimento sobre a importância e a maneira de fazê-las ou por escolha do usuário. A bota de Unna foi citada como tratamento benéfico e facilitador por suas características na realização do curativo, embora algumas pessoas tenham referido incômodo na utilização.

Diante dos resultados encontrados, além do tratamento clínico, enfatiza-se a necessidade de os profissionais de saúde estarem capacitados para atender e planejar as ações de cuidados, considerando as características individuais e a cultura das pessoas. 


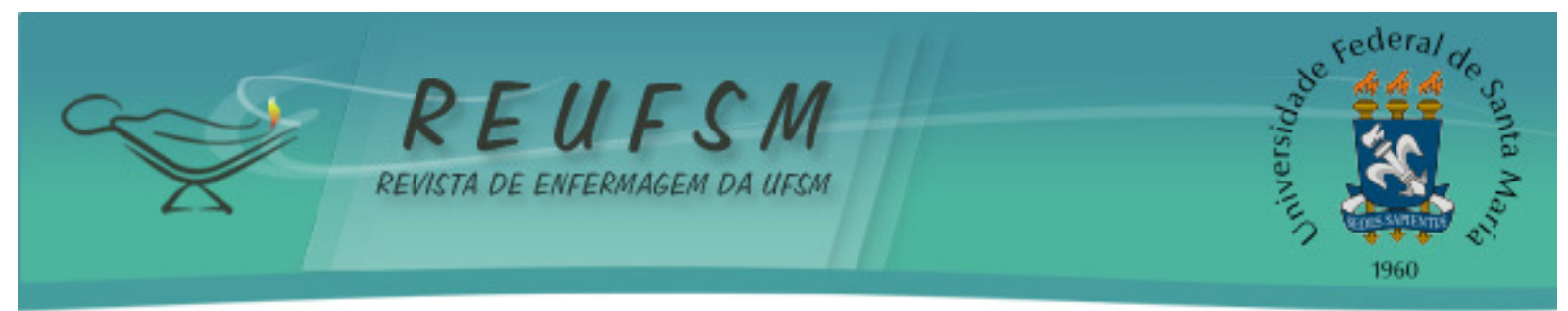

Ainda, faz-se necessário a realização de orientações de forma simples e com linguagem clara e objetiva, a fim de possibilitar o entendimento da pessoa sobre sua doença, buscando seu melhor nível de adaptação e de qualidade de vida.

Como fator limitante, tem-se o fato do estudo ter sido realizado em serviço ambulatorial. Faz-se necessária a ampliação para outros locais, detectando os saberes das pessoas com úlcera venosa, e como estão sendo realizadas as práticas de cuidado.

\section{REFERÊNCIAS}

1. Belczak SQ, Gornati VC, Aun R, Sincos IR, Fragoso H. Tratamento da úlcera varicosa dos membros inferiores mediante cirurgia e bota de Unna: 'uma economia para o sistema de saúde brasileiro. Einstein (São Paulo). 2011;9(3 Pt 1):377-85.

2. Hecke AV, Beeckman D, Grypdonck M, Meuleneire F, Hermie L, Verhaeghe S. Knowledge deficits and information seek behavior in leg ulcer patients: an exploratory qualitative study. J Wound Ostomy Continence Nurs. 2013;40(4):381-7.

3. Milic DJ, Zivic SS, Bogdanovic DC, Perisic ZD, Milosevic ZD, Jankovic RJ, et al. A randomized trial of the Tubulcus multilayer bandaging system in the treatment of extensive venous ulcers. J Vasc Surg. 2007;46(4):750-5.

4. Brito CKD, Nottingham IC, Victor JF, Feitoza SMS, Silva MG, Amaral HEG. Úlcera venosa: avaliação clínica, orientações e cuidados com o curativo. Rev RENE. 2013;14(3):470-80.

5. Souza LB, Torres CA, Pinheiro PNC, Pinheiro AKB. Práticas de educação e saúde no Brasil: a atuação da enfermagem. Rev Enferm UERJ. 2010;18(1)55-60.

6. Moura AA, Nogueira MS. Enfermagem e educação em saúde de hipertensos: revisão da literatura. J Manag Prim Health Care. 2013;4(1):36-41.

7. Malaquias SG, Bachion MM, Sant'ana SMSC, Dallarmi CCB, Lino Junior RS, Ferreira OS. Pessoas com úlceras vasculogênicas em atendimento ambulatorial de enfermagem: estudo das variáveis clínicas e sociodemográficas. Rev Esc Enferm USP. 2012;46(2):302-10.

8. Minayo MCS. O desafio do conhecimento: pesquisa qualitativa em saúde. $12^{a}$ ed. São Paulo: Hucitec-Abrasco; 2013.

9. Angélico RC P, Oliveira AKA, Silva DDN, Vasconcelos QLDQ, Costa I KF, Torres GV. Sociodemographic profile, clinical and health of people with venous ulcers treated at a university hospital. Rev Enferm UFPE Online [Internet]. 2012 [acesso em 2015 abr 20];6(1):62-8. Disponível em: http://www.ufpe.br/revistaenfermagem/index.php/revista/article/view/2100/pdf_759.

10. Macedo EB, Torres GV, Oliveira AA, Medeiros RS, Silva DN, Souza AG. Cost-effectiveness of compression therapy in people with venous ulcers. Rev Enferm UFPE Online [Internet]. 2013[acesso em 2015 abr 20];7(N Esp 10):6101-7. Disponível em: http://www.revista.ufpe.br/revistaenfermagem/index.php/revista/article/viewArticle/4580.

11. Guimarães Barbosa JA, Nogueira Campos LM. Diretrizes para o tratamento da úlcera venosa. Enferm Glob [Internet]. 2010 [acesso em 2015 dez 18];(20). Disponível em: http://scielo.isciii.es/pdf/eg/n20/pt_revision2.pdf.

12. Ferreira T, Costa RP, Souza AM, Souza AC. Aspectos socioeconômicos e clínicos de pacientes com úlcera de perna em uma Unidade Básica de Saúde do Distrito Federal, Brasil. Acta Ciências Saúde. 2012;1(1):7-14. 


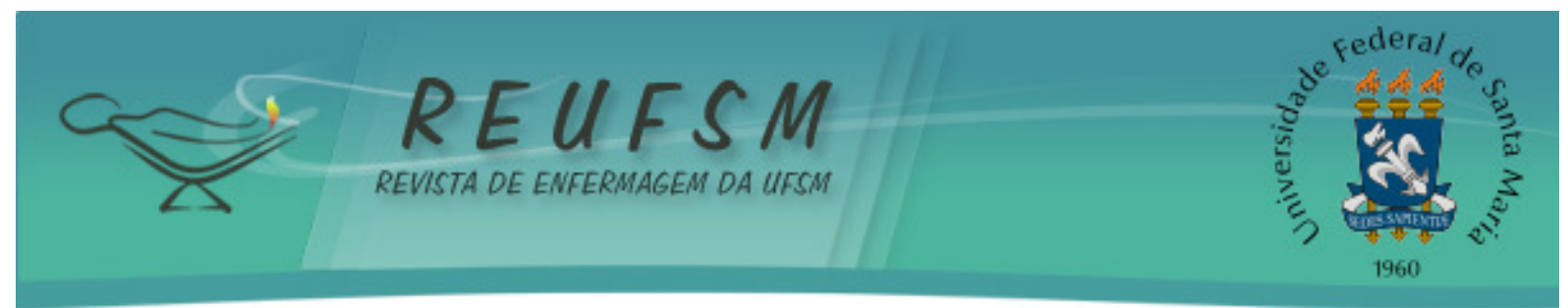

13. Benevides JP, Coutinho JFV, Santos MCL, Oliveira MJA, Vasconcelos FF. Avaliação clínica de úlceras de perna em idosos. Rev RENE. 2012;13(2):300-8.

14. Nottingham IC, Victor JF, Brito CKD, Feitoza SMS, Monteiro LS, Balbino AC. Assessment of biopsychosocial aspects of patients with venous ulcers. Rev Enferm UFPE Online [Internet]. 2012[acesso em 2015 abr 20];6(7):1582-8. Disponível em: http://www.revista.ufpe.br/revistaenfermagem/index.php/revista/article/view/2927.

15. Silva DS, Hahn GV. Cuidados com úlceras venosas: realidade do Brasil e Portugal. Rev Enferm UFSM [Internet]. 2012 [acesso em 2015 abr 20];2(2):330-8. Disponível em: http://cascavel.cpd.ufsm.br/revistas/ojs-2.2.2/index.php/reufsm/article/view/4967.

16. Costa IKF, Nóbrega WG, Costa IKF, Torres GV, Lira ALBC, Tourinho FSV, et al. Pessoas com úlceras venosas: estudo do modo psicossocial do Modelo Adaptativo de Roy. Rev Gaúcha Enferm. 2011;32(3):561-8.

17. Teixeira CES, Retondar JJM. O uso do salto alto por mulheres jovens: entre a biomecânica do movimento e o imaginário da elegância. Corpus et Scientia. 2011;7(1):35-53.

18. Medeiros ABA, Frazão CMFQ, Tinôco JDS, Paiva MGMN, Lopes MVO, Lira ALBC. Venous ulcer: risk factors and the Nursing Outcomes Classification. Invest Educ Enferm. 2014;32(2): 252-9.

19. Queiroz FM, Aroldi JBC, Oliveira GDS, Peres HHC, Santos VLCG. Úlcera venosa e terapia compressiva para enfermeiros: desenvolvimento de curso online. Acta Paul Enferm. 2012;25(3):435-40.

Data de recebimento: $26 / 04 / 2016$

Data de aceite: 10/08/2016

Contato do autor responsável: Marianne Lopes Robaina

Endereço postal: Departamento de Enfermagem do Centro de Ciências da Saúde da Universidade Federal de Santa Maria. Avenida Roraima, 1000. CEP: 97105 - 900 - Santa Maria, Rio Grande do Sul, Brasil.

E-mail: mari.robaina@hotmail.com 